\title{
Factors controlling marine aerosol size distributions and their climate effects over the northwest Atlantic Ocean region
}

\section{Betty Croft et al.}

Correspondence to: Betty Croft (betty.croft@dal.ca) and Jeffrey Pierce (jeffrey.pierce@colostate.edu)

The copyright of individual parts of the supplement might differ from the CC BY 4.0 License. 
Section S1: Role of MSOA. The simulated marine organic vapor source flux for MOSA precursors was tuned to yield an acceptable annual-mean mean fractional error (MFE, 0.5 or less, Boylan and Russell, 2006) between NAAMES campaign-median measurements and simulations (described in Sect. 2). The simulated MBL aerosol size distributions for a set of sources fluxes are shown in Supplementary Fig. S1. Supplementary Table S1 shows the MFEs for this set of source fluxes. Among this set of source fluxes, we found the lowest annual mean MFE for the source flux of 70T-350 ( $\mathrm{T}$ in ${ }^{\circ} \mathrm{C}$ and flux in $\mu \mathrm{g} \mathrm{m}^{-2} \mathrm{~d}^{-1}$ ). We caution that this tuning was specific for the NAAMES region and for a certain GEOS-Chem-TOMAS model configuration. As a result, this source flux may not perform as well in other models, other GEOS-Chem versions and other regions.

All of the temperature dependent parameterizations shown (Supplementary Fig.S1) had acceptable annual mean MFEs for the MBL size distributions, with the exception of 1) the simulation with the factor-of-ten scaling up of the flux that was used in BASE (10x(70T-350)) and 2) the simulation without condensable marine organic vapors (noMSOA). We consider that the order of magnitude of the flux was reasonably constrained for the purposes of this study under the various emission schemes that we tried. However, our findings suggest that further work is needed to better constrain the flux of marine organic vapors.

The selected parameterization also yielded agreement within the $25^{\text {th }}$ to $75^{\text {th }}$ percentiles for the campaign-median vertical profiles in the lowest $1 \mathrm{~km}$ for total aerosol number (N3, N10 and N3N10) and integrated SMPS number, and near-surface OM concentrations (Supplementary Figs. S2-S4). Supplementary Fig. S2 shows slight overprediction outside of these percentiles for the integrated SMPS surface area and volume below $2 \mathrm{~km}$. For the vertical profiles, the mean MFEs across the measurement set were acceptable for the BASE simulation with the 70T-350 source flux and unacceptable for noMSOA (Supplementary Table 2).

Section S2: Mean fractional errors. The MFEs for the for all panels of Figs. 2 through 6 in the main text are shown in Supplementary Table S2. For vertical profiles, the MFEs are calculated using a summation (Eq. 1) over the altitude bins. 
Section S3: Role of new particle formation. A sensitivity simulation with the surrogate nucleation parameterization extended to the surface layer (BASE+BLNUC) increased simulated particle number in the MBL relative to BASE, worsening agreement with measurements (Supplementary Figs. S5-S8 and Supplementary Table S3).

Section S4: Role of ship emissions. We found enhancements in benzene relative to other tracers, such as acetone, which have anthropogenic sources but not associated with ship emissions (Supplementary Fig. S9). These findings are supportive of the study region being influenced by ship emissions.

Section S5: Role of sea spray. Simulated campaign-median sea spray mass concentrations (Supplementary Fig. S10) were within the 3-8 in $\mu \mathrm{g} \mathrm{m}^{-3}$ range with a maximum for NAAMES in March/April 2018, which is in agreement with measurements reported by Saliba et al. (2019). Sensitivity studies with no sea spray and sea spray scaled up by a factor of 3 were conducted. In terms of simulated particle number, the factor-of-3 scaling up of sea spray made a stronger contribution as a condensation sink, suppressing the total particle number in the MBL (Supplementary Figs. S11-S14 and Supplementary Table S4). 


\section{Section S1: Role of MSOA}
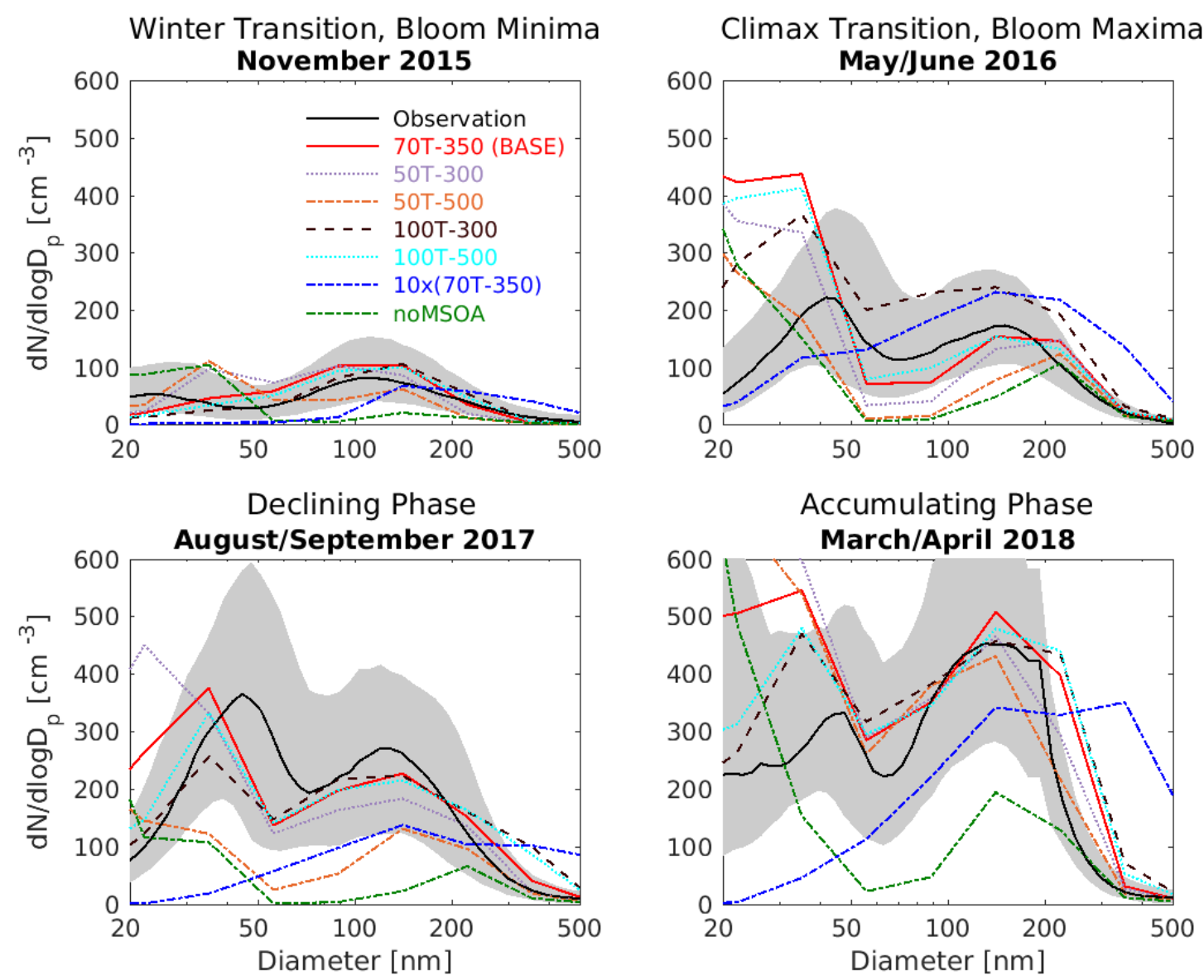

Figure S1: NAAMES cruise-track campaign-median marine boundary layer aerosol size distributions from marine-influenced SEMS observations (black, with $25^{\text {th }}$ to $75^{\text {th }}$ percentiles in grey) and for seven GEOS-Chem-TOMAS simulations with different assumptions for the temperature dependence of the flux of condensable organic vapors (color-coded as shown in legend, flux in $\mu \mathrm{g} \mathrm{m}^{-2} \mathrm{~d}^{-1}$ and $\mathrm{T}$ in ${ }^{\circ} \mathrm{C}$ ). 


\begin{tabular}{|l|c|c|c|c|c|}
\hline $\begin{array}{l}\text { Marine organic } \\
\text { vapor source }\end{array}$ & $\begin{array}{l}\text { Nov 2015 } \\
\text { Bloom Minima }\end{array}$ & $\begin{array}{l}\text { May/June 2016 } \\
\text { Bloom Maxima }\end{array}$ & $\begin{array}{l}\text { Aug/Sept 2017 } \\
\text { Declining Phase }\end{array}$ & $\begin{array}{l}\text { Mar/Apr 2018 } \\
\text { Accumulating }\end{array}$ & $\begin{array}{l}\text { Annual } \\
\text { Mean }\end{array}$ \\
\hline $\mathbf{7 0 T - 3 5 0}$ (BASE) & 0.20 & 0.33 & 0.04 & 0.28 & 0.23 \\
\hline $\mathbf{5 0 T - 3 0 0}$ & 0.34 & 0.22 & 0.22 & 0.21 & 0.25 \\
\hline $\mathbf{5 0 T - 5 0 0}$ & 0.55 & 0.20 & 0.56 & 0.23 & 0.38 \\
\hline $\mathbf{1 0 0 T - 3 0 0}$ & 0.11 & 0.54 & 0.26 & 0.33 & 0.31 \\
\hline $\mathbf{1 0 0 T - 5 0 0}$ & 0.13 & 0.30 & 0.19 & 0.31 & 0.27 \\
\hline noMSOA & 0.76 & 0.31 & 0.84 & 0.59 & 0.63 \\
\hline $\mathbf{1 0 x}(\mathbf{7 0 T}-350)$ & 0.87 & 0.80 & 0.73 & 0.60 & 0.75 \\
\hline
\end{tabular}

Table S1: Mean fractional error (MFE) between observations and seven GEOS-Chem-TOMAS simulations for the ship-track campaign-median aerosol size distributions shown in Supplementary Fig. S1 ( $\mathrm{T}$ in ${ }^{\circ} \mathrm{C}$ and source flux in $\left.\mu \mathrm{g} \mathrm{m}^{-2} \mathrm{~d}^{-1}\right)$. 

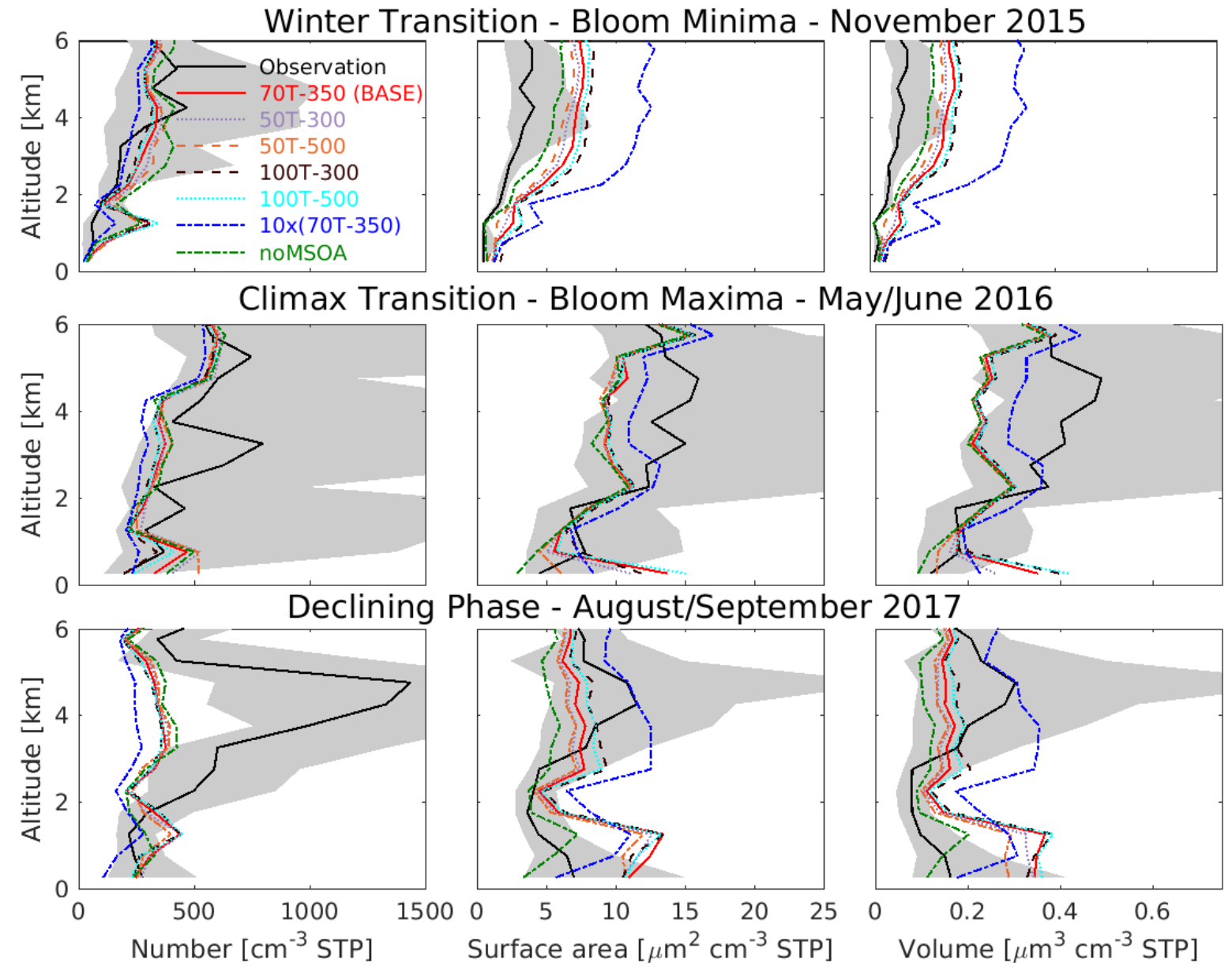

Figure S2: Vertical profiles of NAAMES campaign-median integrated SMPS observations at standard temperature and pressure (STP) for particles with diameters of 10 to $282 \mathrm{~nm}$ (black, with $25^{\text {th }}-75^{\text {th }}$ percentiles in grey) and at STP for seven GEOS-Chem-TOMAS simulations with different assumptions for the temperature dependence of the flux of condensable marine organic vapors (color-coded as shown in legend, flux in $\mu \mathrm{g} \mathrm{m}^{-2} \mathrm{~d}^{-1}$ and $\mathrm{T}$ in ${ }^{\circ} \mathrm{C}$ ). All measurement and model output are binned at $500 \mathrm{~m}$ resolution and campaign-median values plotted at the mid-point of each bin starting at $250 \mathrm{~m}$ above the surface. Lines show linear interpolation between these values. 

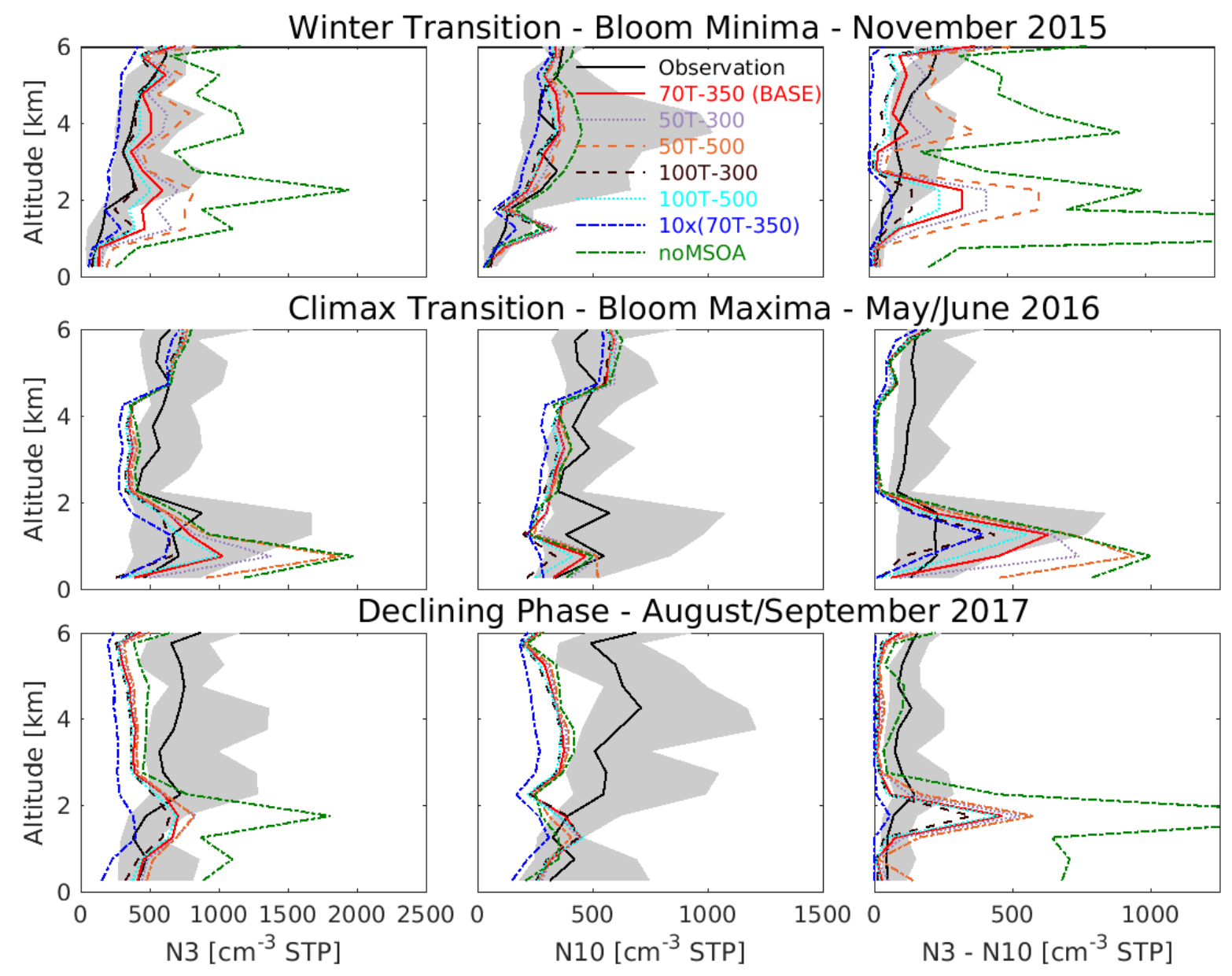

Figure S3: Vertical profiles of NAAMES campaign-median total number concentrations for particles with diameters larger than $3 \mathrm{~nm}(\mathrm{~N} 3), 10 \mathrm{~nm}(\mathrm{~N} 10)$ and between 3 to $10 \mathrm{~nm}(\mathrm{~N} 3-\mathrm{N} 10)$ from CPC observations at standard temperature and pressure (STP) (black, with $25^{\text {th }}-75^{\text {th }}$ percentiles in grey) and at STP for seven GEOS-Chem-TOMAS simulations with different assumptions for the temperature dependence of the flux of condensable marine organic vapors (color-coded as shown in legend, flux in $\mu \mathrm{g} \mathrm{m}^{-2} \mathrm{~d}^{-1}$ and $\mathrm{T}$ in ${ }^{\circ} \mathrm{C}$ ). All measurement and model output are binned at $500 \mathrm{~m}$ resolution and campaign-median values plotted at the mid-point of each bin starting at $250 \mathrm{~m}$ above the surface. Lines show linear interpolation between these values. 

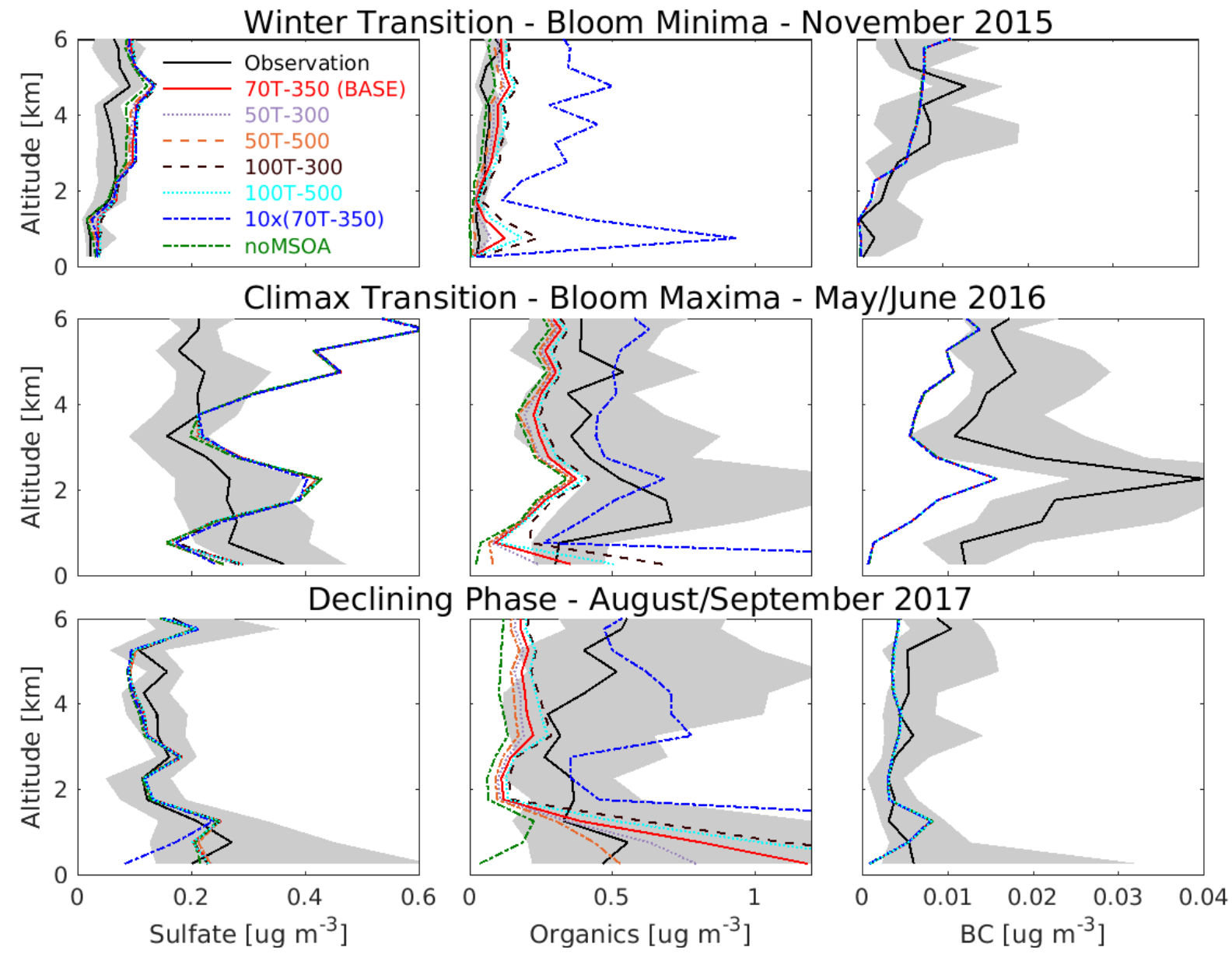

Figure S4: Vertical profiles of NAAMES campaign-median aerosol non-refractory sulfate and organic mass concentrations from Aerosol Mass Spectrometer and refractory black carbon from SP2 observations at standard temperature and pressure (STP) (black, with $25^{\text {th }}-75^{\text {th }}$ percentiles in grey) and at STP for seven GEOS-Chem-TOMAS simulations with different assumptions for the temperature dependence of the flux of marine condensable organic vapors (color-coded as shown in legend, flux in $\mu \mathrm{g} \mathrm{m}^{-2} \mathrm{~d}^{-1}$ and $\mathrm{T}$ in ${ }^{\circ} \mathrm{C}$ ). Simulated sulfate shown is non-sea-salt-sulfate. All measurement and model output are binned at $500 \mathrm{~m}$ resolution and campaign-median values plotted at the mid-point of each bin starting at $250 \mathrm{~m}$ above the surface. Lines show linear interpolation between these values. 
Section S2: Mean fractional errors

\begin{tabular}{|c|c|c|c|c|c|c|}
\hline MFEs for figure panels & BASE & noABLNUC & noMSOA & noDMS & noSHIP & noSS \\
\hline \multicolumn{7}{|l|}{2015} \\
\hline MBL size dist. Fig 2 & 0.20 & 0.95 & 0.76 & 0.44 & 0.31 & 0.31 \\
\hline Number Fig 3 & 0.31 & 0.39 & 0.40 & 0.26 & 0.25 & 0.30 \\
\hline Surface area Fig 3 & 0.43 & 0.68 & 0.73 & 0.43 & 0.44 & 0.43 \\
\hline Volume Fig 3 & 1.22 & 1.04 & 0.96 & 1.12 & 1.21 & 1.22 \\
\hline N3 Fig 4 & 0.51 & 0.75 & 1.02 & 0.43 & 0.44 & 0.53 \\
\hline N10 Fig 4 & 0.24 & 0.43 & 0.23 & 0.20 & 0.24 & 0.25 \\
\hline N3-N10 Fig 4 & 0.88 & 1.04 & 1.34 & 0.90 & 0.92 & 0.87 \\
\hline Sulfate Fig 5 & 0.39 & 0.26 & 0.25 & 0.27 & 0.34 & 0.39 \\
\hline Organic mass Fig 5 & 0.52 & 0.51 & 0.73 & 0.52 & 0.52 & 0.53 \\
\hline Black carbon Fig 5 & 0.44 & 0.45 & 0.45 & 0.44 & 0.44 & 0.44 \\
\hline DMS Fig 6 & 0.12 & 0.12 & 0.12 & 0.67 & 0.40 & 0.12 \\
\hline Average of 2015 & 0.42 & 0.68 & 0.67 & 0.50 & 0.46 & 0.45 \\
\hline \multicolumn{7}{|l|}{2016} \\
\hline MBL size dist. Fig 2 & 0.33 & 0.51 & 0.31 & 0.27 & 0.13 & 0.24 \\
\hline Number Fig 3 & 0.37 & 0.60 & 0.38 & 0.43 & 0.34 & 0.37 \\
\hline Surface area Fig 3 & 1.04 & 1.10 & 1.16 & 1.09 & 1.06 & 1.04 \\
\hline Volume Fig 3 & 0.50 & 0.46 & 0.39 & 0.44 & 0.49 & 0.50 \\
\hline N3 Fig 4 & 0.35 & 0.74 & 0.43 & 0.62 & 0.36 & 0.37 \\
\hline N10 Fig 4 & 0.31 & 0.61 & 0.31 & 0.47 & 0.34 & 0.30 \\
\hline N3-N10 Fig 4 & 1.08 & 1.48 & 1.10 & 1.40 & 1.11 & 1.10 \\
\hline Sulfate Fig 5 & 0.52 & 0.52 & 0.52 & 0.16 & 0.56 & 0.52 \\
\hline Organic mass Fig 5 & 0.60 & 0.61 & 0.84 & 0.59 & 0.60 & 0.60 \\
\hline Black carbon Fig 5 & 0.78 & 0.78 & 0.78 & 0.78 & 0.78 & 0.78 \\
\hline DMS Fig 6 & 0.26 & 0.26 & 0.26 & 0.67 & 0.31 & 0.26 \\
\hline Average of 2016 & 0.50 & 0.66 & 0.53 & 0.55 & 0.46 & 0.49 \\
\hline \multicolumn{7}{|l|}{2017} \\
\hline MBL size dist. Fig 2 & 0.04 & 0.89 & 0.84 & 0.43 & 0.23 & 0.12 \\
\hline Number Fig 3 & 0.60 & 0.91 & 0.50 & 0.73 & 0.60 & 0.61 \\
\hline Surface area Fig 3 & 0.88 & 1.12 & 1.18 & 1.02 & 0.91 & 0.87 \\
\hline Volume Fig 3 & 0.78 & 0.61 & 0.56 & 0.67 & 0.77 & 0.79 \\
\hline N3 Fig 4 & 0.43 & 0.86 & 0.49 & 0.69 & 0.47 & 0.45 \\
\hline N10 Fig 4 & 0.58 & 0.97 & 0.49 & 0.81 & 0.59 & 0.56 \\
\hline N3-N10 Fig 4 & 1.09 & 1.47 & 1.01 & 1.40 & 1.11 & 1.04 \\
\hline Sulfate Fig 5 & 0.17 & 0.18 & 0.17 & 0.27 & 0.19 & 0.17 \\
\hline Organic mass Fig 5 & 0.65 & 0.65 & 1.03 & 0.63 & 0.66 & 0.66 \\
\hline Black carbon Fig 5 & 0.47 & 0.48 & 0.48 & 0.47 & 0.47 & 0.47 \\
\hline DMS Fig 6 & 0.18 & 0.18 & 0.20 & 0.67 & 0.20 & 0.18 \\
\hline Average of 2017 & 0.43 & 0.78 & 0.68 & 0.65 & 0.49 & 0.45 \\
\hline Average all years & 0.45 & 0.71 & 0.63 & 0.57 & 0.47 & 0.46 \\
\hline
\end{tabular}


Table S2: Mean fractional error (MFE) between the six simulations described in Table 1 and the measurements for the panels of Figs. 2 through 6. Results for Fig. 2 are weighted to include MFEs for first four moments of the MBL aerosol size distributions. All MFEs are calculated for altitude below $6 \mathrm{~km}$, except below $2 \mathrm{~km}$ for DMS due to the decrease over orders of magnitude above 2 $\mathrm{km}$. The MFEs are calculated following Eq. 1 with a summation over the altitude bins that are defined in Sect.2. 


\section{Section S3: Role of new particle formation}
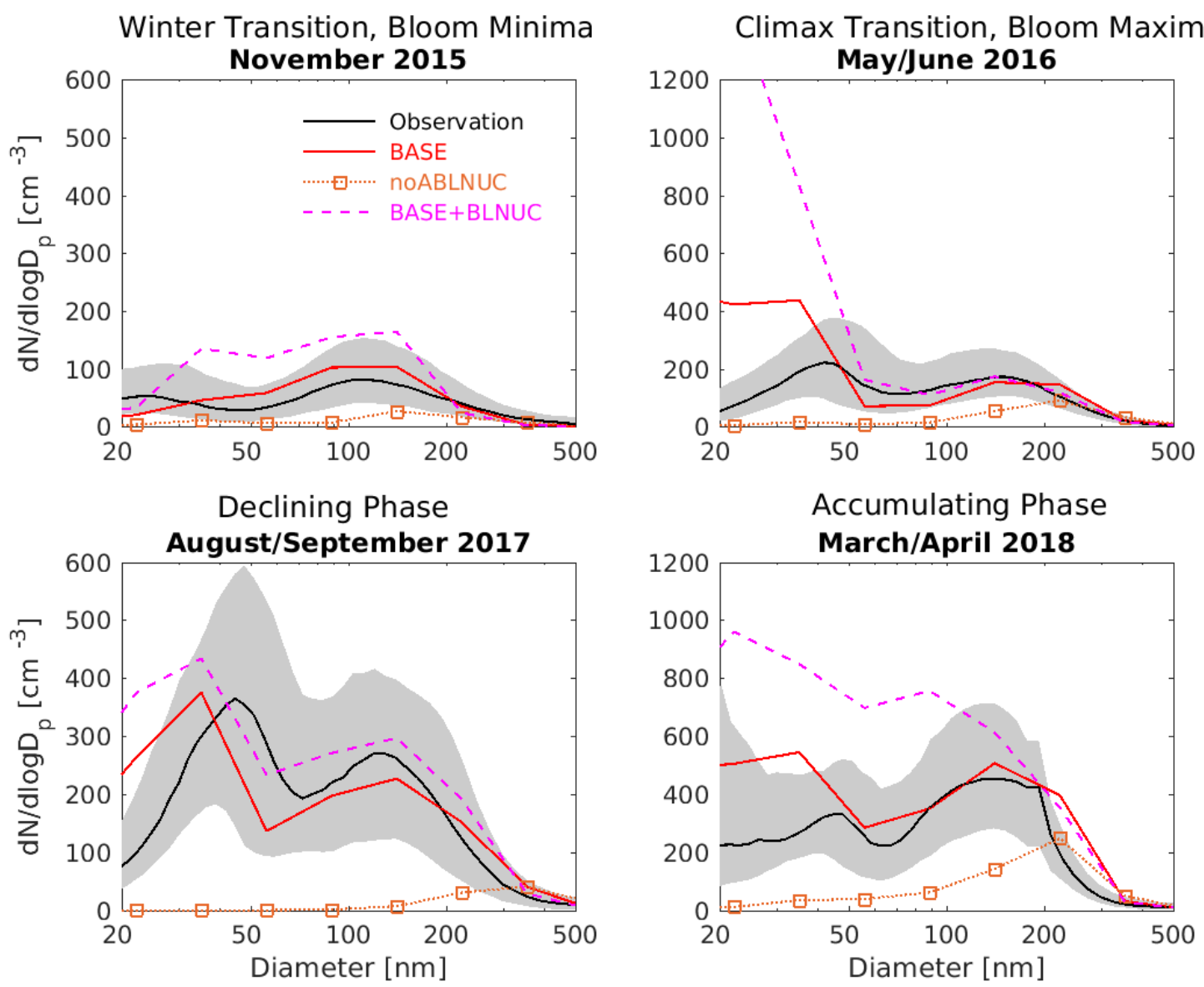

Figure S5: NAAMES cruise-track campaign-median marine boundary layer aerosol size distributions from marine-influenced SEMS observations (black, with $25^{\text {th }}$ to $75^{\text {th }}$ percentiles in grey) and for three GEOS-Chem-TOMAS simulations with different assumptions for surrogate above boundary layer nucleation. noABLNUC: surrogate activation nucleation scheme above the boundary removed; BASE+BLNUC: surrogate activation nucleation scheme extended from $2 \mathrm{~km}$ to the surface layer; BASE as described in Table 1 and Section 2, including surrogate activation nucleation scheme from above the boundary layer to $2 \mathrm{~km}$. 


\begin{tabular}{|l|c|c|c|c|c|}
\hline & $\begin{array}{l}\text { Nov 2015 } \\
\text { Bloom Minima }\end{array}$ & $\begin{array}{l}\text { May/June 2016 } \\
\text { Bloom Maxima }\end{array}$ & $\begin{array}{l}\text { Aug/Sept 2017 } \\
\text { Declining Phase }\end{array}$ & $\begin{array}{l}\text { Mar/Apr 2018 } \\
\text { Accumulating }\end{array}$ & $\begin{array}{l}\text { Annual } \\
\text { Mean }\end{array}$ \\
\hline BASE & 0.20 & 0.33 & 0.04 & 0.28 & 0.21 \\
\hline noABLNUC & 0.95 & 0.54 & 0.89 & 0.50 & 0.72 \\
\hline BASE+BLNUC & 0.36 & 0.56 & 0.20 & 0.48 & 0.40 \\
\hline
\end{tabular}

Table S3: Mean fractional error between observations and three GEOS-Chem-TOMAS simulations for the ship-track campaign-median aerosol size distributions shown in Supplementary Fig. S5. 

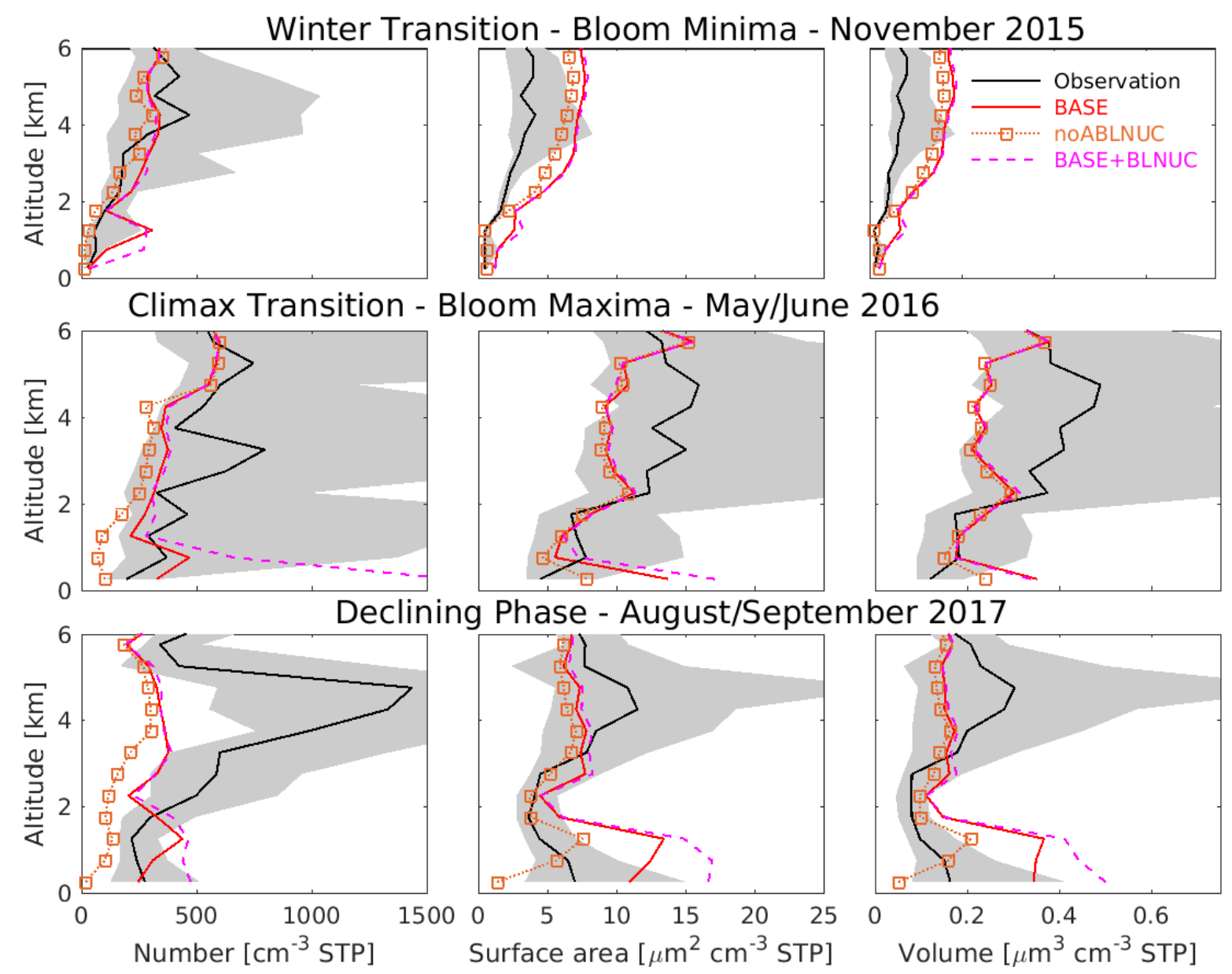

Figure S6: Vertical profiles of NAAMES campaign-median integrated SMPS observations at standard temperature and pressure (STP) for particles with diameters of 10 to $282 \mathrm{~nm}$ (black, with $25^{\text {th }}-75^{\text {th }}$ percentiles in grey) and at STP for three GEOS-Chem-TOMAS simulations with different assumptions for above boundary layer nucleation. noABLNUC: surrogate activation nucleation scheme above the boundary removed; BASE+BLNUC: surrogate activation nucleation scheme extended from $2 \mathrm{~km}$ to the surface layer; BASE as described in Table 1 and Section 2, including surrogate activation nucleation scheme from above the boundary layer to $2 \mathrm{~km}$. All measurement and model output are binned at $500 \mathrm{~m}$ resolution and campaign-median values plotted at the midpoint of each bin starting at $250 \mathrm{~m}$ above the surface. Lines show linear interpolation between these values. 

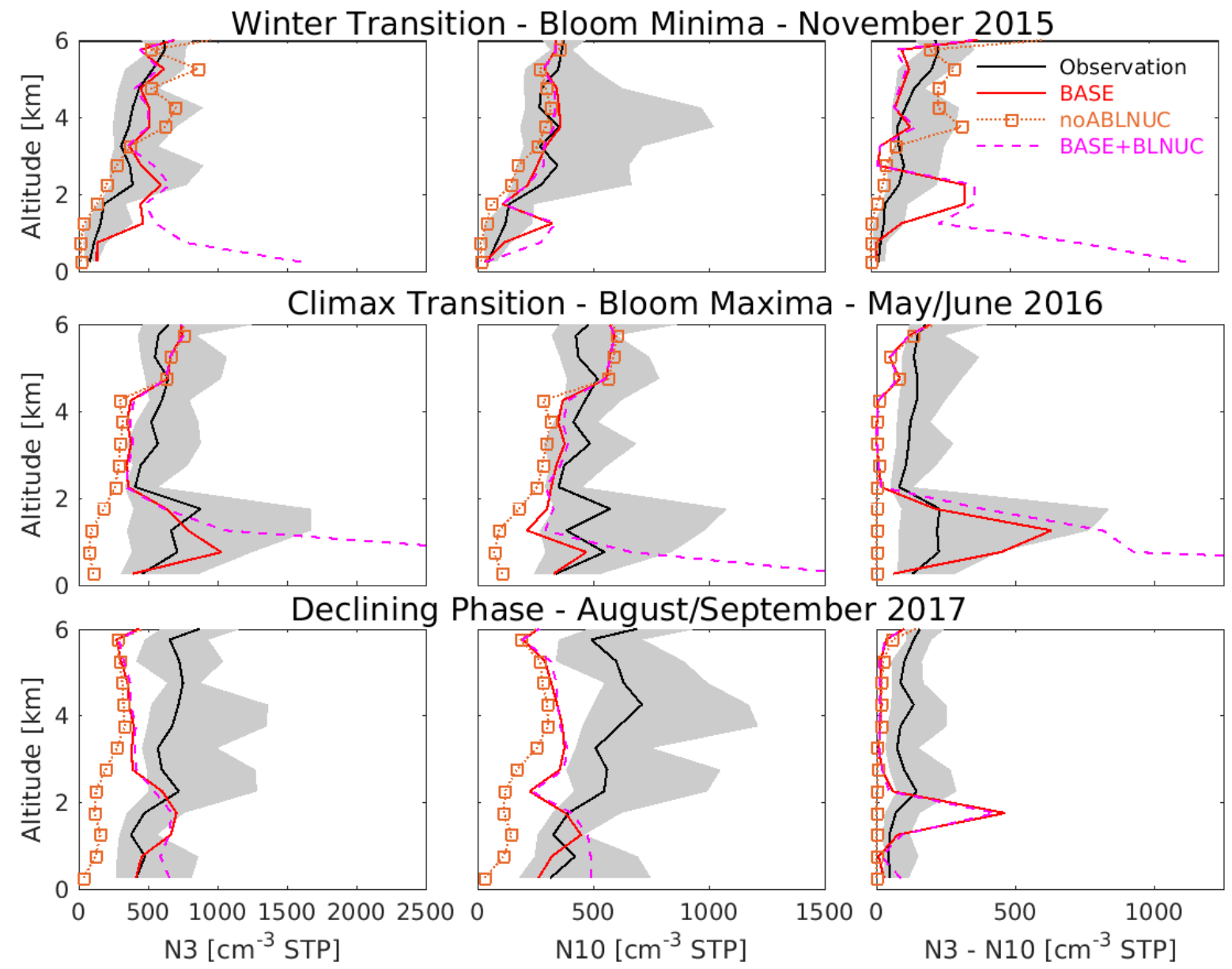

Figure S7: Vertical profiles of NAAMES campaign-median total number concentrations for particles with diameters larger than $3 \mathrm{~nm}(\mathrm{~N} 3), 10 \mathrm{~nm}(\mathrm{~N} 10)$ and between 3 to $10 \mathrm{~nm}(\mathrm{~N} 3-\mathrm{N} 10)$ from CPC observations at standard temperature and pressure (STP) (black, with $25^{\text {th }}-75^{\text {th }}$ percentiles in grey) and at STP for three GEOS-Chem-TOMAS simulations with different assumptions for above boundary layer nucleation. noABLNUC: surrogate activation nucleation scheme above the boundary removed; BASE+BLNUC: surrogate activation nucleation scheme extended from $2 \mathrm{~km}$ to the surface layer; BASE as described in Table 1 and Section 2, including surrogate activation nucleation scheme from above the boundary layer to $2 \mathrm{~km}$. All measurement and model output are binned at $500 \mathrm{~m}$ resolution and campaign-median values plotted at the midpoint of each bin starting at $250 \mathrm{~m}$ above the surface. Lines show linear interpolation between these values. 

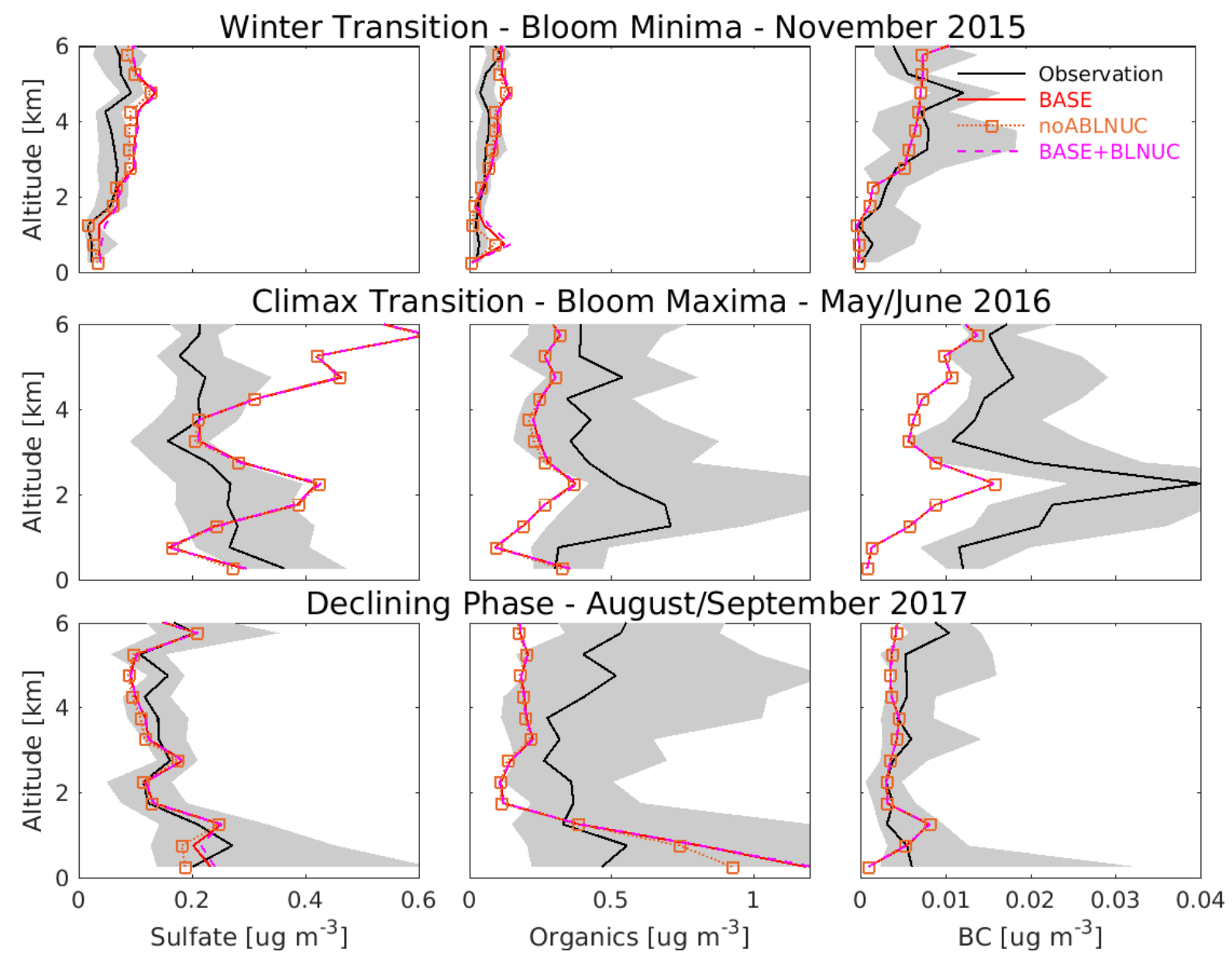

Figure S8: Vertical profiles of NAAMES campaign-median aerosol non-refractory sulfate and organic mass concentrations from Aerosol Mass Spectrometer and refractory black carbon from SP2 observations at standard temperature and pressure (STP) (black, with $25^{\text {th }}-75^{\text {th }}$ percentiles in grey) and at STP for three GEOS-Chem-TOMAS simulations with different assumptions for above boundary layer nucleation. noABLNUC: surrogate activation nucleation scheme above the boundary removed; BASE+BLNUC: surrogate activation nucleation scheme extended from $2 \mathrm{~km}$ to the surface layer; BASE as described in Table 1 and Section 2, including surrogate activation nucleation scheme from above the boundary layer to $2 \mathrm{~km}$. All measurement and model output are binned at $500 \mathrm{~m}$ resolution and campaign-median values plotted at the mid-point of each bin starting at $250 \mathrm{~m}$ above the surface. Lines show linear interpolation between these values. 


\section{Section S4: Role of ship emissions}
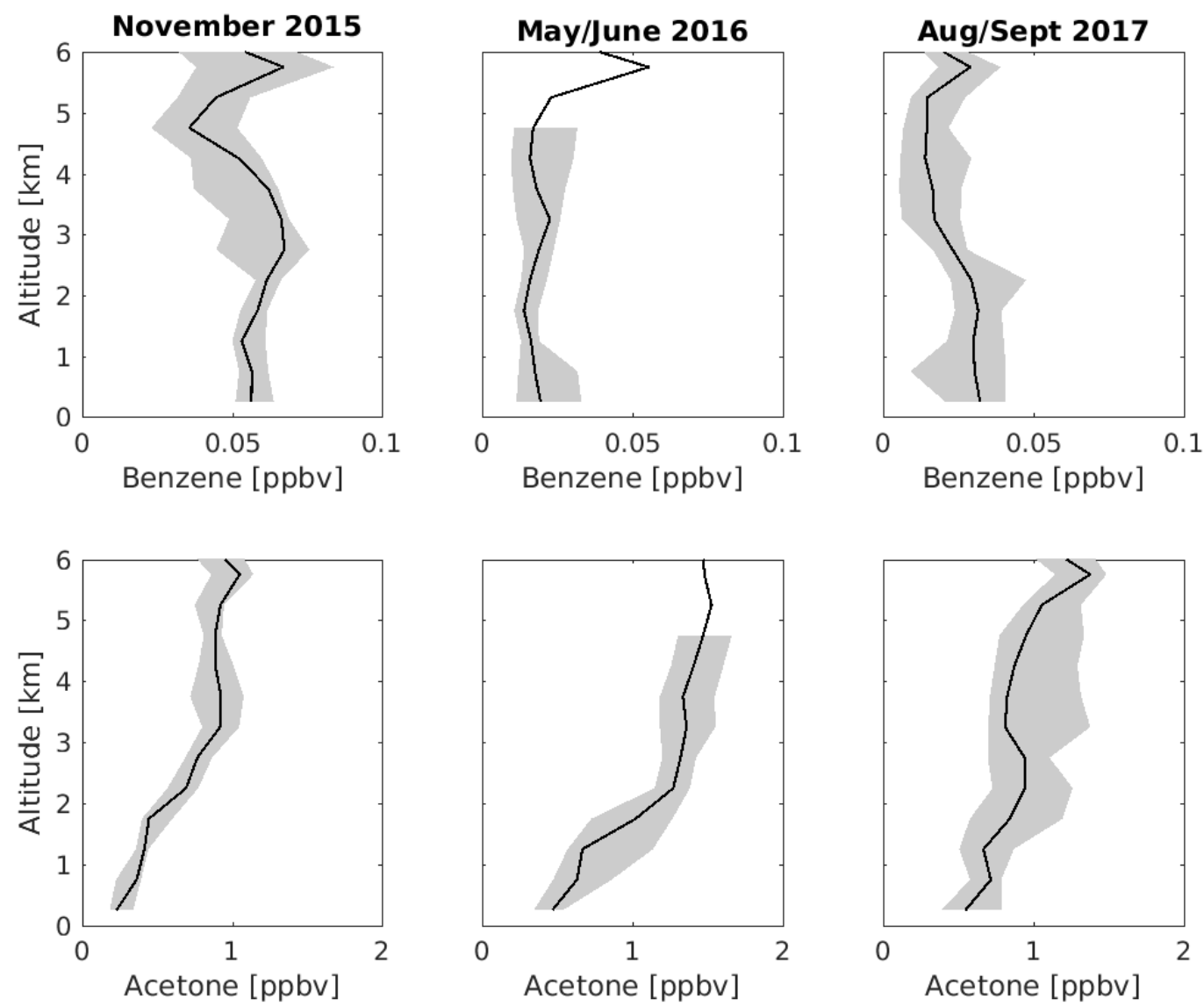

Figure S9: Vertical profiles of NAAMES campaign-median benzene (top row) and acetone (bottom row) mixing ratios obtained from a Proton-Transfer-Reaction Time-of-Flight Mass Spectrometer (PTR-ToF-MS) aboard the NASA C130 aircraft (black, with $25^{\text {th }}-75^{\text {th }}$ percentiles in grey). All measurements are binned at $500 \mathrm{~m}$ resolution and campaign-median values plotted at the mid-point of each bin starting at $250 \mathrm{~m}$ above the surface. Lines show linear interpolation between these values. 
Section S5: Role of sea spray
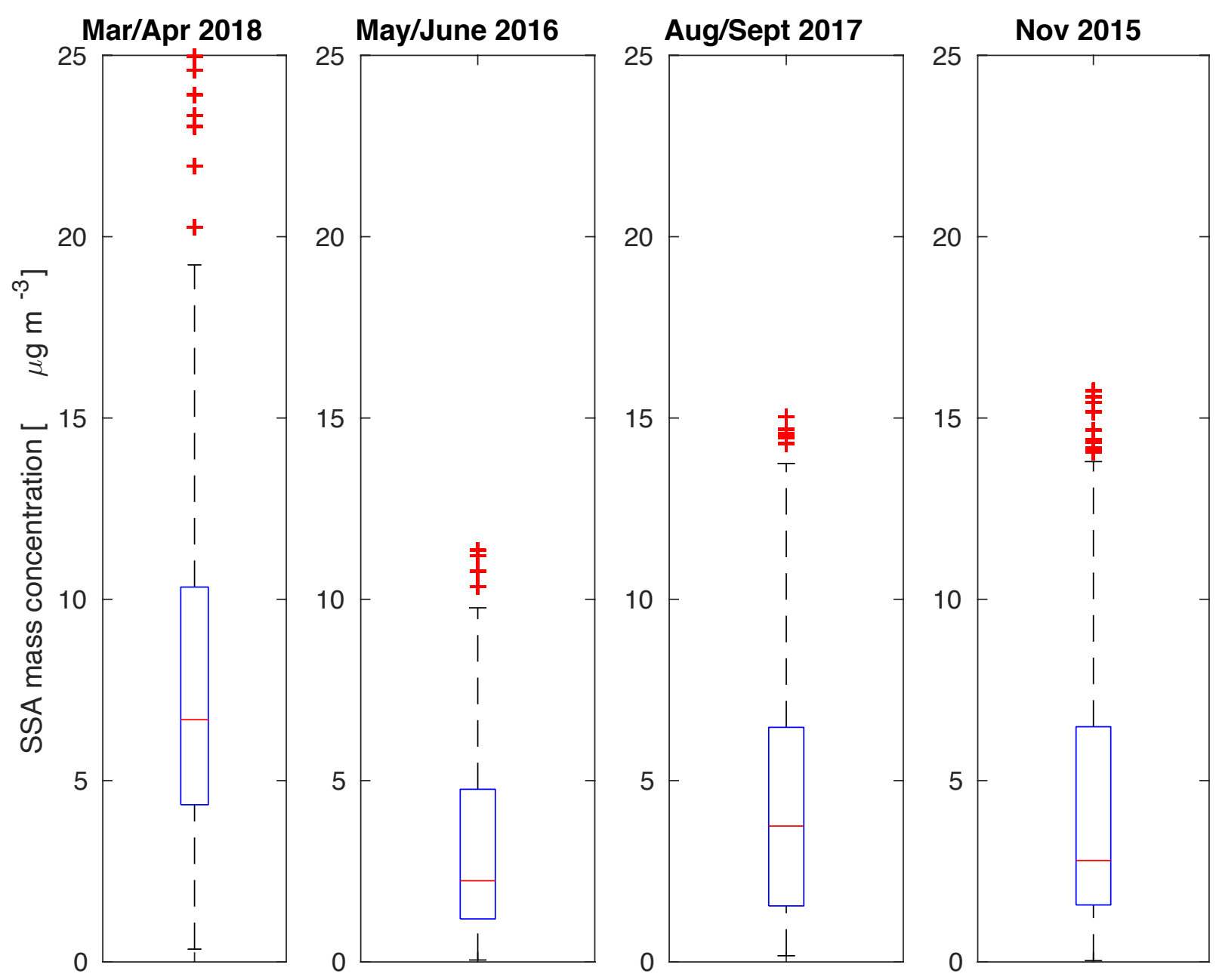

Figure S10: Box plots of simulated ship-track campaign-median sea spray aerosol mass concentrations for the four years of the NAAMES campaigns for simulation BASE. Red line shows median and box limits are $25^{\text {th }}$ and $75^{\text {th }}$ percentiles. Outliers are shown with red plus symbol. 

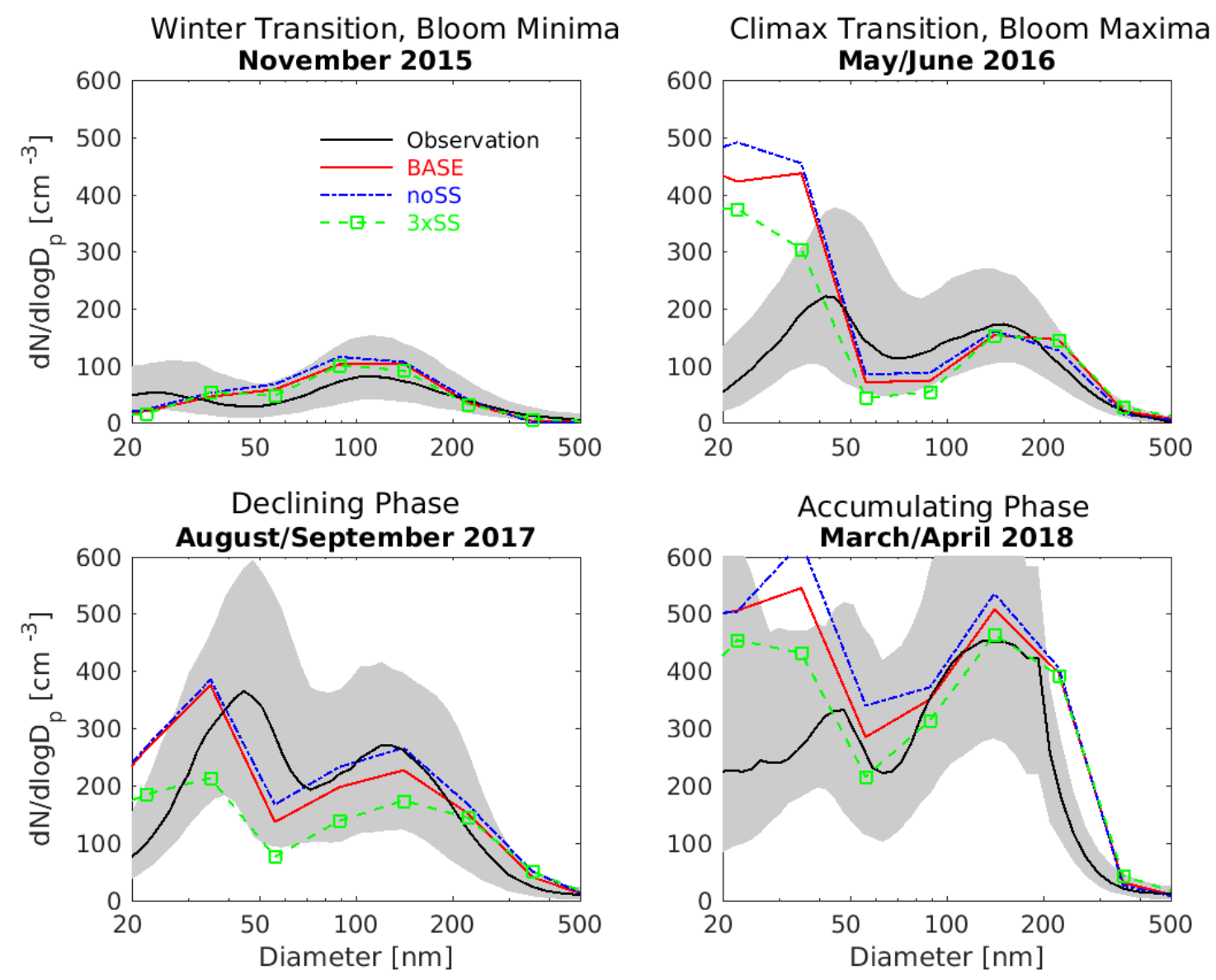

Figure S11: NAAMES cruise-track campaign-median marine boundary layer aerosol size distributions from marine-influenced SEMS observations (black, with $25^{\text {th }}$ to $75^{\text {th }}$ percentiles in grey) and for three GEOS-Chem-TOMAS simulations with different assumptions for the sea spray emissions. noSS: no sea spray emissions; 3xSS: sea spray emissions scaled up by 3; BASE as described in Table 1 and Section 2. 


\begin{tabular}{|l|c|c|c|c|c|}
\hline & $\begin{array}{l}\text { Nov 2015 } \\
\text { Bloom Minima }\end{array}$ & $\begin{array}{l}\text { May/June 2016 } \\
\text { Bloom Maxima }\end{array}$ & $\begin{array}{l}\text { Aug/Sept 2017 } \\
\text { Declining Phase }\end{array}$ & $\begin{array}{l}\text { Mar/Apr 2018 } \\
\text { Accumulating }\end{array}$ & $\begin{array}{l}\text { Annual } \\
\text { Mean }\end{array}$ \\
\hline BASE & 0.20 & 0.33 & 0.04 & 0.28 & 0.21 \\
\hline noSS & 0.31 & 0.24 & 0.12 & 0.28 & 0.24 \\
\hline 3xSS & 0.05 & 0.38 & 0.14 & 0.28 & 0.21 \\
\hline
\end{tabular}

Table S4: Mean fractional error between observations and three GEOS-Chem-TOMAS simulations for the ship-track campaign-median aerosol size distributions shown in Supplementary Fig. S11. 



Figure S12: Vertical profiles of NAAMES campaign-median integrated SMPS observations aboard aircraft at standard temperature and pressure (STP) for particles with diameters of 10 to $282 \mathrm{~nm}$ (black, with $25^{\text {th }}-75^{\text {th }}$ percentiles in grey) and at STP for three GEOS-Chem-TOMAS simulations with different assumptions for the sea spray emissions. noSS: no sea spray emissions; 3xSS: sea spray emissions scaled up by 3; BASE as described in Table 1 and Section 2. All measurement and model output are binned at $500 \mathrm{~m}$ resolution and campaign-median values plotted at the mid-point of each bin starting at $250 \mathrm{~m}$ above the surface. Lines show linear interpolation between these values. 

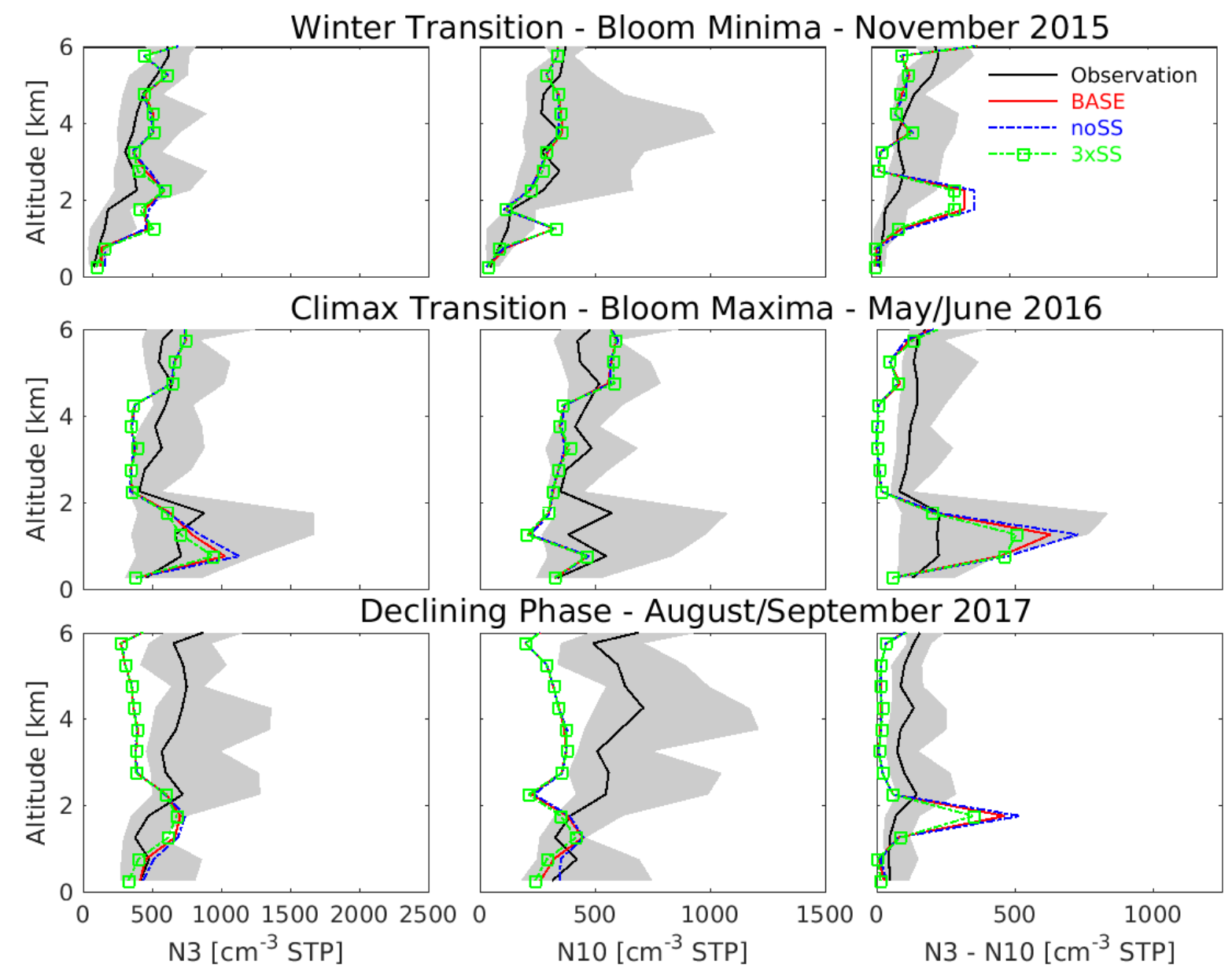

Figure S13: Vertical profiles of NAAMES campaign-median total number concentrations for particles with diameters larger than $3 \mathrm{~nm}(\mathrm{~N} 3), 10 \mathrm{~nm}(\mathrm{~N} 10)$ and between 3 to $10 \mathrm{~nm}(\mathrm{~N} 3-\mathrm{N} 10)$ from CPC observations board aircraft at standard temperature and pressure (STP) (black, with $25^{\text {th }}$ $75^{\text {th }}$ percentiles in grey) and at STP for three GEOS-Chem-TOMAS simulations with different assumptions for the sea spray emissions. noSS: no sea spray emissions; 3xSS: sea spray emissions scaled up by 3; BASE as described in Table 1 and Section 2. All measurement and model output are binned at $500 \mathrm{~m}$ resolution and campaign-median values plotted at the mid-point of each bin starting at $250 \mathrm{~m}$ above the surface. Lines show linear interpolation between these values. 

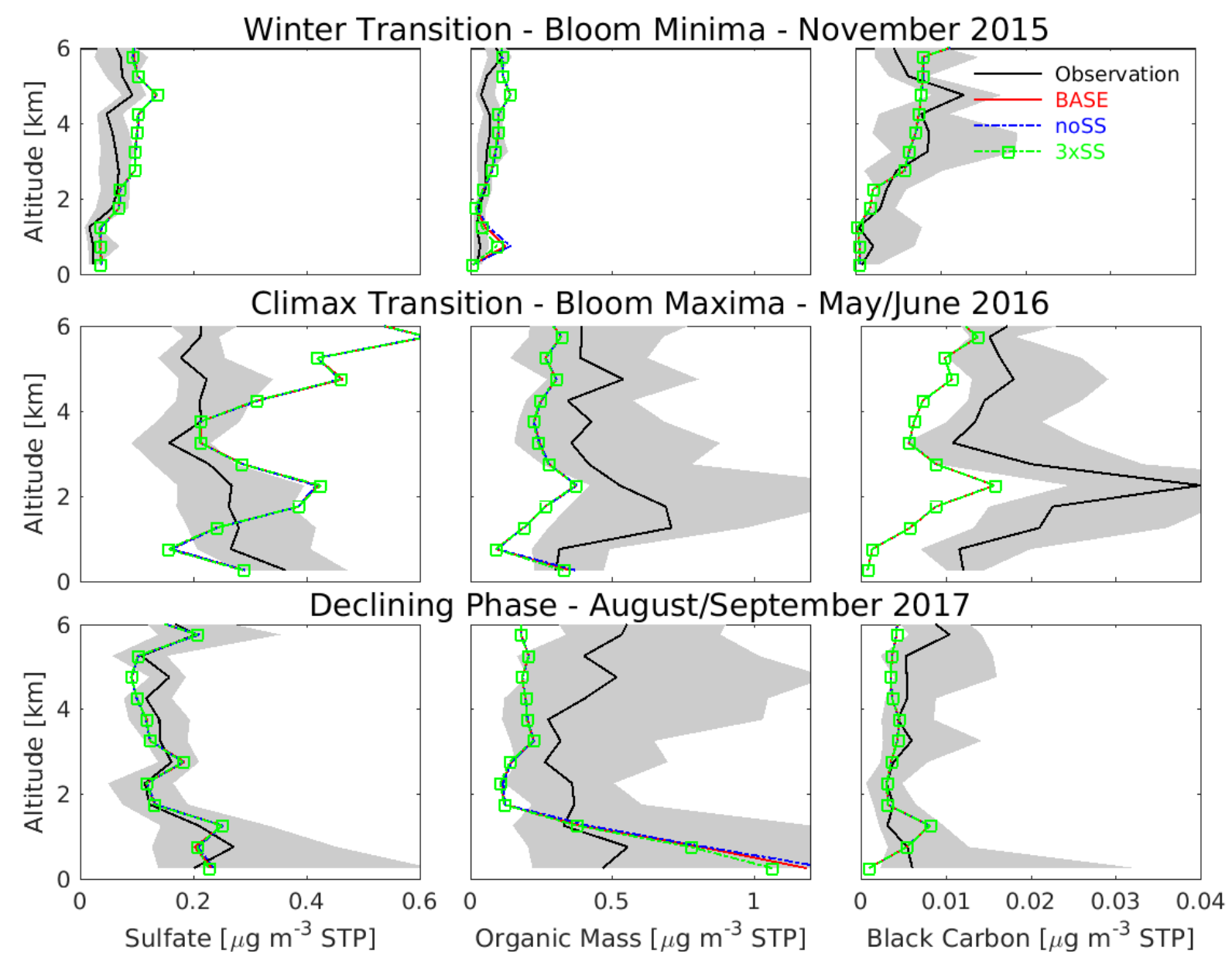

Figure S14: Vertical profiles of NAAMES campaign-median aerosol non-refractory sulfate and organic mass concentrations from Aerosol Mass Spectrometer and refractory black carbon from SP2 observations aboard aircraft at standard temperature and pressure (STP) (black, with $25^{\text {th }}-75^{\text {th }}$ percentiles in grey) and at STP for three GEOS-Chem-TOMAS simulations with different assumptions for the sea spray emissions. noSS: no sea spray emissions; 3xSS: sea spray emissions scaled up by 3; BASE as described in Table 1 and Section 2. All measurement and model output are binned at $500 \mathrm{~m}$ resolution and campaign-median values plotted at the mid-point of each bin starting at $250 \mathrm{~m}$ above the surface. Lines show linear interpolation between these values. 